\title{
QSAR-АНАЛІЗ БІБЛІОТЕК 4-ТІАЗОЛІДИНОН-СПОРІДНЕНИХ ГЕТЕРОЦИКЛІВ ДЛЯ ПРОГНОЗУВАННЯ ПРОТИТРИПАНОСОМНИХ ВЛАСТИВОСТЕЙ НОВИХ ПОХІДНИХ
}

Вступ. Похідні тіазолідинону та споріднених гетероциклів $\epsilon$ джерелом нових протипаразитарних агентів, у тому числі молекул із протитрипаносомними властивостями. В актуальних наукових джерелах знайдено ряд досліджень про кількісний взаємозв'язок структура - протитрипаносомна активність, що включають різні підходи комп'ютерної хімії. Більшість досліджень належить до так званих мультитаргетних, коли до вибірки включають результати інших видів протипаразитарних активностей. Розробка нових QSAR-моделей похідних тіазолідинону з протитрипаносомними властивостями дозволить окреслити напрямки спрямованого дизайну нових протипаразитарних агентів на основі циклів тіазолу та тіазолідинону.

Мета дослідження - встановити кількісний взаємозв'язок структура - протитрипаносомна активність у межах бібліотек тіазолідинонів та споріднених гетероциклів.

Meтоди дослідження. Побудову математичних моделей на основі QSAR-аналізу здійснювали за допомогою онлайн-платорорми Online Chemical Database.

Результати й обговорення. Аналіз кількісного взаємозв'язку структура - протитрипаносомна активність проводили із застосуванням математичної моделі асоціативних нейронних мереж (ASNN: Associative Neural Networks) та методу регресії Random Forest (RFR: Random Forest regression) на основі вибірок, що включали похідні ізотіокумарин-3-карбонових кислот, тіопіранотіазолів і 4-тіазолідинон-імідазотіадіазолів із встановленою трипаноцидною активністю щодо Trypanosoma brucei brucei ma Trypanosoma brucei gambiense. Кращу прогнозувальну здатність для групи ізотіокумарин-3-карбонових кислот і тіопірано[2,3-d][1,3]тіазол-2-онів обчислено за допомогою алгоритму Random Forest. Модель, обчислена на основі алгоритму Random Forest для групи імідазотіадіазолів, володіє найвищою прогнозувальною здатністю зі значенням $R^{2}=0,96$.

Висновок. На основі методів асоціативних нейронних мереж та регресії Random Forest розроблено прог ностичні моделі для прогнозування протипаразитарної активності диверсифрікованих похідних 4-тіазолідинонів і подальшого фокусування напрямків оптимізації нових біологічно активних молекул із трипаноцидними властивостями.

КЛЮчОВІ СЛОВА: QSAR-аналіз; метод асоціативних нейронних мереж; метод регресії Random Forest; тіазолідони; протитрипаносомна активність.

ВСТУП. Афрриканський трипаносомоз - це трансмісивна інфекційна хвороба, яку викликають найпростіші паразити: Trypanosoma brucei gambiense ( $\mathrm{Tb}$ gambiense) i Trypanosoma brucei rhodesiense (Tb rhodesiense) [1, 2]. Захворювання швидко розвивається, уражає центральну нервову систему і спричиняє неврологічні ураження та нейропсихічні порушення. При відсутності відповідної терапії захворювання, яке викликав один із двох паразитів, призводить до коми та смерті [1]. Безперервні зусилля ВОО3, урядових та, в більшості випадків, неурядових організацій, скеровані на боротьбу з африканським трипаносомозом, сприяли суттєвому (․ А. П. Крищишин-Дилевич, 2020. зменшенню кількості зареєстрованих випадків у 2009 р. вона знизилася до 10 000, вперше за 50 років. Цей тренд зберігається до сьогодні -у 2019 р. зареєстровано менше ніж 1000 випадків, хоча кількість людей, які перебувають у зоні ризику інорекції, становить близько 65 млн [3].

Часто тропічні хвороби є поза увагою великих фрар мацевтичних компаній, і пошуком нових активних і малотоксичних протитрипаносомних агентів на основі гетероциклічних "лікоподібних" молекул займаються малі академічні групи, до яких належить і наукова група кафедри фрармацевтичної, органічної та біоорганічної хімії Львівського національного медичного університету імені Данила Галицького. Серед таких малих 
молекул тіосемікарбазони, їх комплекси з металами і тіазоли, які можна розглядати як циклічні аналоги тіосемікарбазону, широко вивчено, i вони володіють достатньо добрими трипаноцидними властивостями [4]. Похідні тіазолідинону та споріднених гетероциклів $є$ джерелом нових протипаразитарних агентів, у тому числі молекул із протитрипаносомними властивостями [5]. В актуальних наукових джерелах знайдено ряд досліджень про кількісний взаємозв'язок структура - протитрипаносомна активність, що включають різні підходи комп'ютерної хімії [6]. Так, наприклад, описано CoMFA дослідження активності 26 біфоссфонатів щодо Tb rhodesiense [7] та COMFA дослідження інгібіторів трипанотіон редуктази Trypanosoma brucei [8]. Більшість досліджень належить до так званих мультитаргетних, коли до вибірки включають результати інших видів протипаразитарних активностей $[9,10]$.

Мета дослідження - встановити кількісний взаємозв'язок структура - протитрипаносомна активність у межах бібліотек ізотикумаринів, тіопіранотіазолів та 4-тіазолідинон-імідазотіадіазолів для фрормування теоретичних елементів раці онального дизайну протитрипаносомних засобів на основі тіазолу/тіазолідинону.

МЕТОДИ ДОСЛІДЖЕННЯ. Побудову математ и чних моделей методами асоціативних нейр онних мереж (ASNN: Associative Neural Networks) та perpeciï Random Forest (RFR:
Random Forest regression) здійснювали за допомогою онлайн-платфрорми Online Chemical Database [11].

РЕЗУЛЬТАТИ Й ОБГОВОРЕННЯ. ДЛЯ пОбУдови математичних моделей відібрано сполуки різних груп конденсованих та неконденсованих похідних тіазолу/тіазолідинону, а також ряд ізотіокумаринів із встановленою протитрипаносомною дією на $T b$ brucei й Tb gambiense. Інгібуючу акт и вність ряду ізотіокумарин-3-карбонових кис л от 1-15 [12], N-фрункціоналізованих $(5 \mathrm{a} R, 11 \mathrm{~b} R)-3,5 \mathrm{a}, 6,11 \mathrm{~b}$-тетрагідро-2H,5H-хромено[4',3':4,5]тіопірано[2,3-d][1,3]тіазол-2-онів 1624 [13] та низки 6,6,7-тризаміщених тіопірано[2,3-d][1,3]тіазолів 25-35 [14] щодо Tb brucei виражено у відсотках при дії досліджуваних сполук у концентрації 10 мг/мл. Перша вибірка (№ 1) включала 24 сполуки (1-24), друга (№ 2) 35 сполук (1-35) (рис. 1), які розподілили на навчальні й тренувальні набори у співвідношенні 80:20. Іншим класом сполук, на основі яких проводили аналіз кількісного взаємозв'язку структура - активність і здійснювали побудову QSAR-моделей, були 4-тіазолідинон-імідазотіадіазоли 36-60 [15], їх інгібуючу дію вивчали на Tb gambiense, величину IC ${ }_{50}$ виражали у мкM. Група 4-тіазолідинон-імідазотіадіазолів (вибірка № 3) включала 25 сполук (36-60) (рис. 2), розподіл на навчальні й тренувальні набори здійснювали також у співвідношенні 80:20.

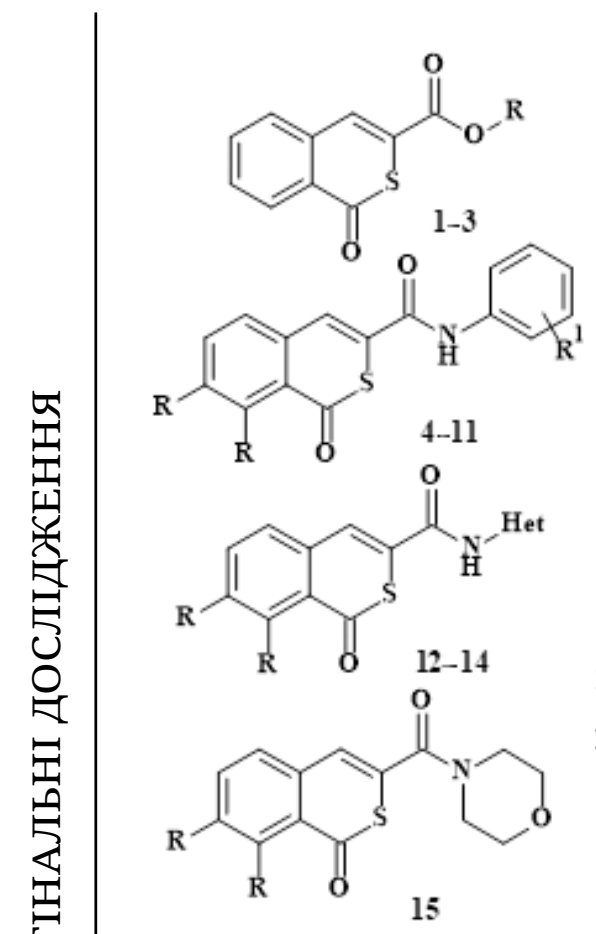

$1 \mathrm{R}=\mathrm{H}$

$2 \mathrm{R}=\mathrm{OMe}$

$3 \mathrm{R}=\mathrm{NHCH} \cdot \mathrm{COOH}$

$\mathrm{R}=\mathrm{H}$

$4 \mathrm{R}^{\prime}=3-\mathrm{CF}_{3}$

$5 \mathrm{R}^{1}+\mathrm{C}_{2} \mathrm{H}_{4}=1$-naphthyl

$\mathrm{R}=\mathrm{OMe}$

$6 \mathrm{R}^{\prime}=4 \mathrm{SO}_{2} \mathrm{NH}_{2}$

$7 \mathrm{R}^{\prime}=3-\mathrm{CF}_{3}$

$8 \mathrm{R}^{\prime}=4-\mathrm{COOC}_{2} \mathrm{H}_{5}$

$9 \mathrm{R}^{\prime}+\mathrm{C}_{1} \mathrm{H}_{4}=1$-naphthy'

$10 \mathrm{R}^{1}=4-\mathrm{Cl}$

$11 \mathrm{R}^{\mathrm{l}}=2-\mathrm{CF}_{3}$
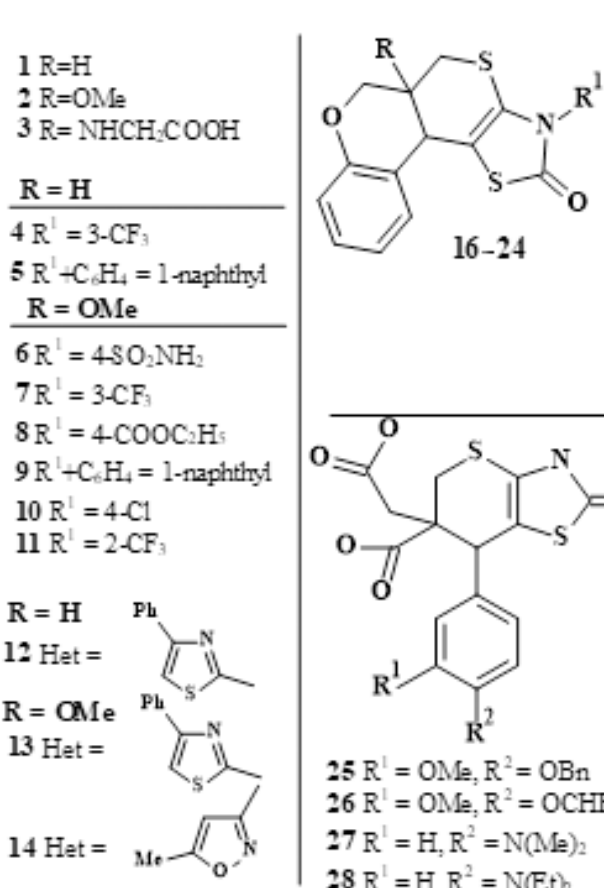

$\mathrm{R}=\mathrm{H}$

$\overline{16 \mathrm{R}^{\prime}=\mathrm{CH}: \mathrm{CO}-\left(4-\mathrm{F}-\mathrm{C}_{2} \mathrm{H}_{4}\right)}$

$17 \mathrm{R}^{1}=\mathrm{CH}_{2} \mathrm{CO}-\left(4-\mathrm{Cl}^{-} \mathrm{C}_{2} \mathrm{H}_{4}\right)$

$18 \mathrm{R}^{1}=\mathrm{CH}_{2} \mathrm{CONH}_{2}$

$19 \mathrm{R}^{\prime}=\mathrm{CH}_{2} \mathrm{CONH}-\left(2-\mathrm{CF}_{3}-\mathrm{C}_{6} \mathrm{H}_{4}\right)$

$20 \mathrm{R}^{1}=\mathrm{CH}_{2} \mathrm{CONH}-\left(2,4-\mathrm{Cl}_{2}-\mathrm{C}_{6} \mathrm{H}_{3}\right)$

$21 \mathrm{R}^{\prime}=\mathrm{CH}_{2} \mathrm{CONH}-\left(4-\mathrm{COMe}_{2} \mathrm{CH}_{4}\right)$

$22 \mathrm{R}^{\prime}=\left(\mathrm{CH}_{2}\right)_{2} \mathrm{CN}$

$\mathrm{R}=\mathrm{Me}$

$23 \mathrm{R}^{\prime}=\mathrm{CH}_{2} \mathrm{CONH}-\left(4-\mathrm{COOEt}-\mathrm{C}_{2} \mathrm{H}_{4}\right)$

$22 \mathrm{R}^{\prime}=\mathrm{CH}_{2} \mathrm{CONH}-\left(4-\mathrm{Cl}_{-} \mathrm{C}_{2} \mathrm{H}_{4}\right)$

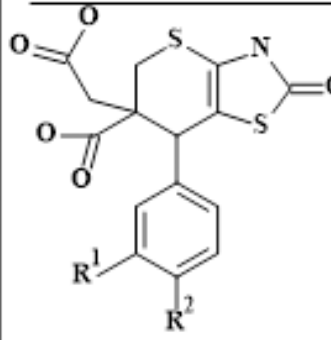

$25 \mathrm{R}^{1}=\mathrm{OMe}, \mathrm{R}^{2}=\mathrm{OBn}$

$26 \mathrm{R}^{1}=\mathrm{OMe}^{2} \mathrm{R}^{2}=\mathrm{OCHF}_{2}$

$27 \mathrm{R}^{1}=\mathrm{H}, \mathrm{R}^{2}=\mathrm{N}(\mathrm{Me})_{2}$

$28 \mathrm{R}^{1}=\mathrm{H}, \mathrm{R}^{2}=\mathrm{N}\left(\mathrm{E} \mathrm{t}_{2}\right.$

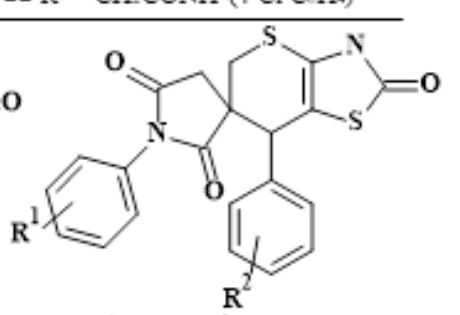

$29 \mathrm{R}^{1}=4-\mathrm{Cl} \mathrm{R}^{2}=4-\mathrm{OME}$

$30 \mathrm{R}^{1}=4-\mathrm{Cl}^{2} \mathrm{R}^{2}=3,4-(\mathrm{OMe})_{2}$

$31 \mathrm{R}^{1}=4-\mathrm{Cl} \mathrm{R}^{2}=4-\mathrm{N}(\mathrm{E} \mathrm{t})_{2}$

$32 \mathrm{R}^{1}=4-\mathrm{Cl}, \mathrm{R}^{2}=4-\mathrm{N}(\mathrm{Me})_{2}$

$33 \mathrm{R}^{1}=4-\mathrm{Cl} \mathrm{R}^{2}=2-\mathrm{OH}$

$34 \mathrm{R}=4-\mathrm{OH} \cdot \mathrm{R}^{2}=2-\mathrm{OH}$

$35 \mathrm{R}^{1}=3-\mathrm{Me} \cdot \mathrm{R}^{2}=2-\mathrm{OH}$

Рис. 1. Структури ізотіокумарин-3-карбонових кислот і тіопіранотіазолів, що ввійшли до вибірок № 1-2. 


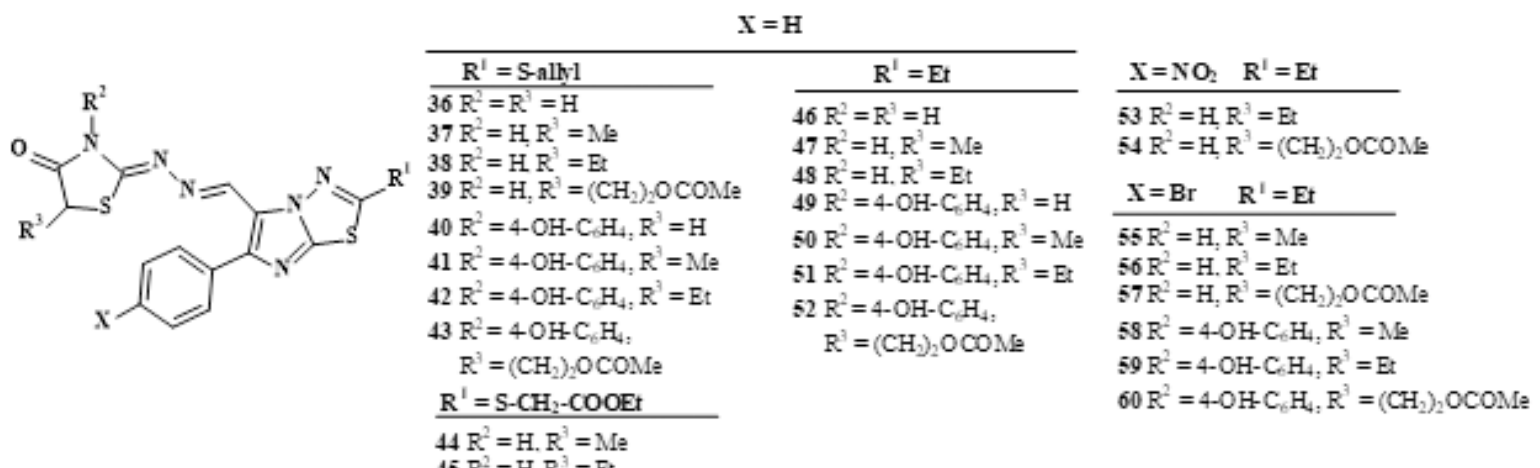

Рис. 2. Структури імідазотіадіазолів, що ввійшли до вибірки № 3.

Аналіз кількісного взаємозв'язку структура акт ивність проводили декількома методами, зокрема із застосуванням математичної моделі асоціативних нейронних мереж (ASNN: Associative Neural Networks) та методу регресії Random Forest (RFR: Random Forest regression) [11]. Метод множинної лінійної регресії (MLR: Multiple Linear Regression) та метод часткових найменших квадратів (PLS: Partial Least Squares) не дозволили отримати моделі із задовільною чи високою прогнозувальною здатністю (результатів не наведено в роботі).

Попередню обробку молекул здійснювали за допомогою стандартних процедур Chemaxon. Залежно від моделі як дескриптори обчислювали індекси атомів і зв'язків, ALogPS, а також деякі 3D дескриптори: конституційні, топологічні та індекси лікоподібності, вирахувані за програмою DRA G ON v.7. Для відсіювання дескрипторів дотримувалися таких умов, як: і) видалення дескрипторів з менше ніж двома унікальними значеннями; іi) видалення дескрипторів, що мають абсолютні значення, більші ніж 999999; іii) видалення дескрипторів, що мають розбіжність, меншу ніж 0,01; iv) групування дескрипторів, що мають попарні коефіцієнти кореляції Пірсона $R$, вищі за 0,95.

Валідацію всіх моделей здійснювали методом N-кратної крос-валідації (5 тестувань). Ступінь неузгодженості між моделлю та експериментальними даними навчального набору визначали шляхом обчислення кореня із середньоквадратичної похибки (RMSE, Root Mean Squared Error) та середньої абсолютної похибки (MAE, Mean Absolute Error).

Для моделі асоціативних нейронних мереж (ASNN) застосовано тренувальний метод SuperSAB, кількість нейронів у прихованому шарі - 3, кількість ітерацій навчання - 1000, кількість ансамблів нейронів - 64. Додатковими параметрами були розподіл = 3 та селекція = 2 . Для методу регресії Random Forest (RFR) кількість дерев (ntrees) становила 512. Обчислені дані для математичних моделей асоціативних нейронних мереж (ASNN) та методу регресії Random Forest (RFR) для всіх наборів сполук, які вивчали, наведено в таблиці.

Кращу прогнозувальну здатність для наборів сполук, які містили похідні ізотіокумарин-3-карбонових кислот 1-15 та N-заміщених тіопіра-

Таблиця - Параметри прогнозувальної здатності QSAR-моделей для наборів похідних ізотіокумарин-3-кумаринових кислот, тіопіранотіазолів і 4-тіазолідинон-імідазотіадіазолів; кількість відібраних дескрипторів для кожної з моделей

\begin{tabular}{|c|c|c|c|c|c|c|c|}
\hline $\begin{array}{c}\text { № } \\
\text { 3a/ח }\end{array}$ & Модель & Вибірка & $\begin{array}{c}\text { Кількість } \\
\text { відібраних } \\
\text { дескрипторів }\end{array}$ & $\mathrm{R}^{2}$ & $\mathrm{Q}^{2}$ & RMSE & MAE \\
\hline & & № 1 & & & & & \\
\hline \multirow[t]{2}{*}{1} & $A S N N$ & Train. set & \multirow[t]{2}{*}{19} & $0,7 \pm 0,1$ & $0,7 \pm 0,1$ & $21 \pm 3$ & $17 \pm 3$ \\
\hline & & Test set & & $0,5 \pm 0,3$ & $0,3 \pm 0,4$ & $30 \pm 10$ & $20 \pm 10$ \\
\hline \multirow[t]{3}{*}{2} & $R F R$ & Train. set & \multirow[t]{2}{*}{38} & $0,7 \pm 0,1$ & $0,6 \pm 0,1$ & $23 \pm 3$ & $20 \pm 3$ \\
\hline & & Test set & & $0,9 \pm 0,2$ & $0,8 \pm 0,3$ & $16 \pm 2$ & $15 \pm 2$ \\
\hline & & № 2 & & & & & \\
\hline \multirow[t]{2}{*}{3} & $A S N N$ & Train. set & \multirow[t]{2}{*}{24} & $0,5 \pm 0,2$ & $0,5 \pm 0,2$ & $27 \pm 6$ & $18 \pm 4$ \\
\hline & & Test set & & $0,5 \pm 0,3$ & $0,4 \pm 0,3$ & $30 \pm 7$ & $22 \pm 8$ \\
\hline \multirow[t]{3}{*}{4} & RFR & Train. set & \multirow[t]{2}{*}{59} & $0,5 \pm 0,2$ & $0,5 \pm 0,2$ & $27 \pm 5$ & $20 \pm 4$ \\
\hline & & Test set & & $0,6 \pm 0,3$ & $0,5 \pm 0,4$ & $26 \pm 7$ & $21 \pm 6$ \\
\hline & & № 3 & & & & & \\
\hline \multirow[t]{2}{*}{5} & RFR & Train. set & \multirow[t]{2}{*}{31} & $0,02 \pm 0,07$ & $0 \pm 0$ & $0,48 \pm 0,04$ & $0,42 \pm 0,05$ \\
\hline & & Test set & & $0,96 \pm 0,03$ & $0,6 \pm 0,3$ & $0,30 \pm 0,05$ & $0,26 \pm 0,06$ \\
\hline
\end{tabular}


но[2,3-d][1,3]тіазол-2-онів 16-22, обчислено за допомогою алгоритму Random Forest, що підтверджено значеннями $\mathrm{R}^{2}$ та $\mathrm{Q}^{2}$ зі значеннями 0,9 і 0,8 відповідно. Параметри прогнозувальної здатності моделі асоціативних нейронних мереж були нижчими для цих моделей. Загалом прогнозувальна здатність моделей ASNN та RFR для набору сполук № 2, які містили ряд 6,6,7-тризаміщених тіопірано[2,3-d][1,3]тіазолів 16-35, була суттєво нижчою, ніж для моделей, обчислених на основі показників активності та значень дескрипторів сполук з вибірки № 1 (рис. 3).
Статистичні характеристики обчислених математичних моделей асоціативних нейронних мереж (ASNN) та методу регресії Random Forest (RFR) для вибірки імідазотіадіазолів № 3 наведено в таблиці. Генерацію 3D структури молекул для обчислення 3D дескрипторів, включених у модель, розроблену методом регресії Random Forest, проводили за допомогою програмного пакета Corina. Модель, обчислена на основі алгоритмy Random Forest для групи імідазотіадіазолів, володіє найвищою прогнозувальною здатністю зі значенням $\mathrm{R}^{2}=0,96$.

(1)

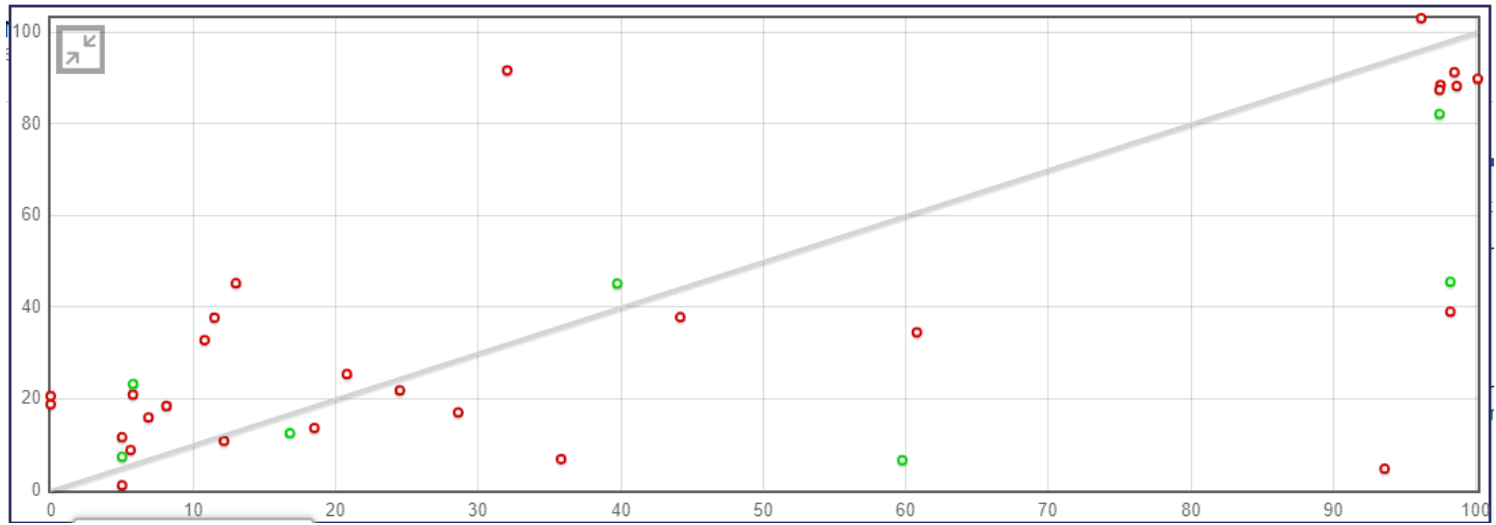

(2)
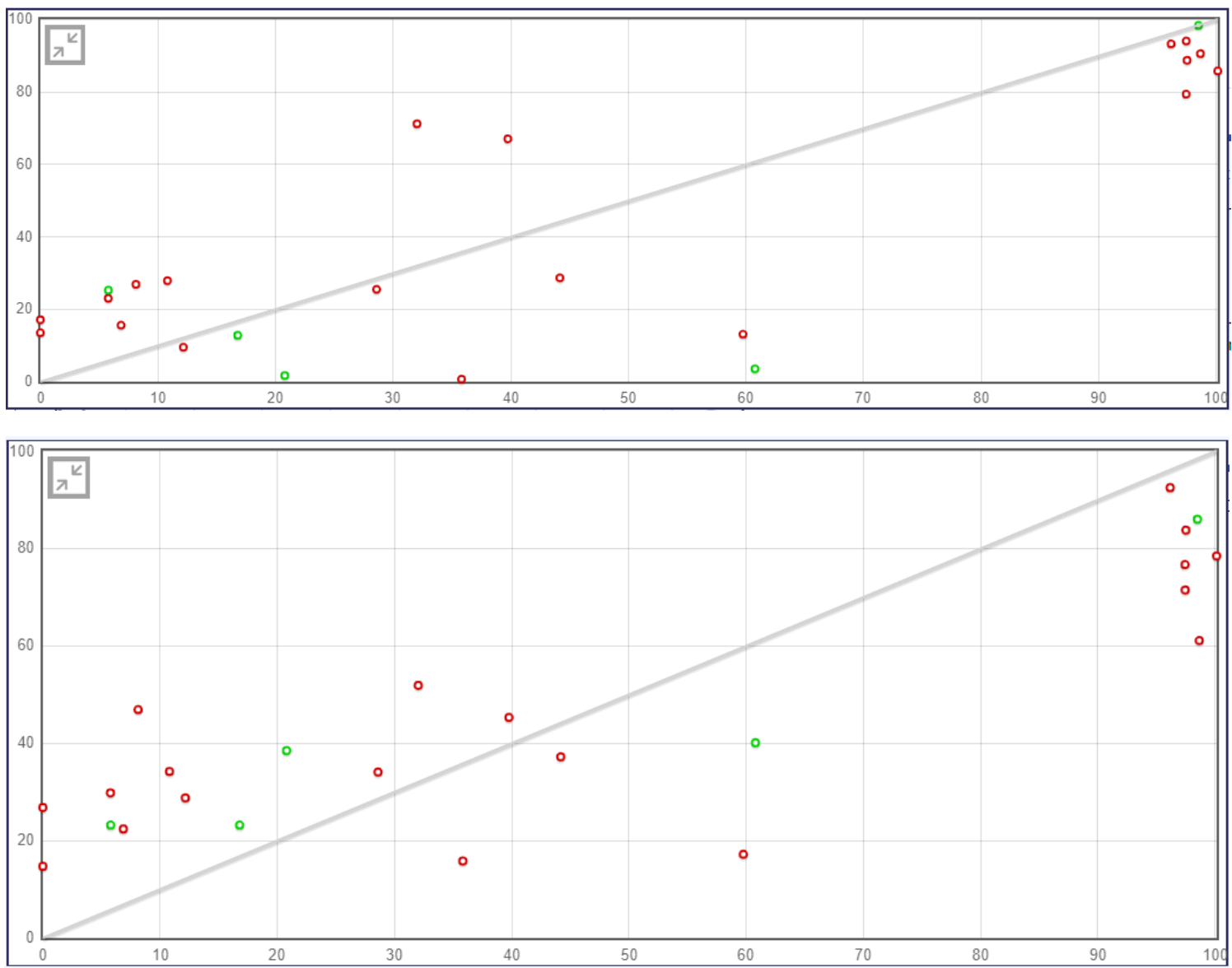

(3)

Рис. 3. Графіки: (1) - модель асоціативних нейронних мереж (ASNN) для вибірки № 1; (2) - модель на основі методу регресії Random Forest для вибірки № 1; (3) - модель асоціативних нейронних мереж (ASNN) для вибірки № 2. 
(4)

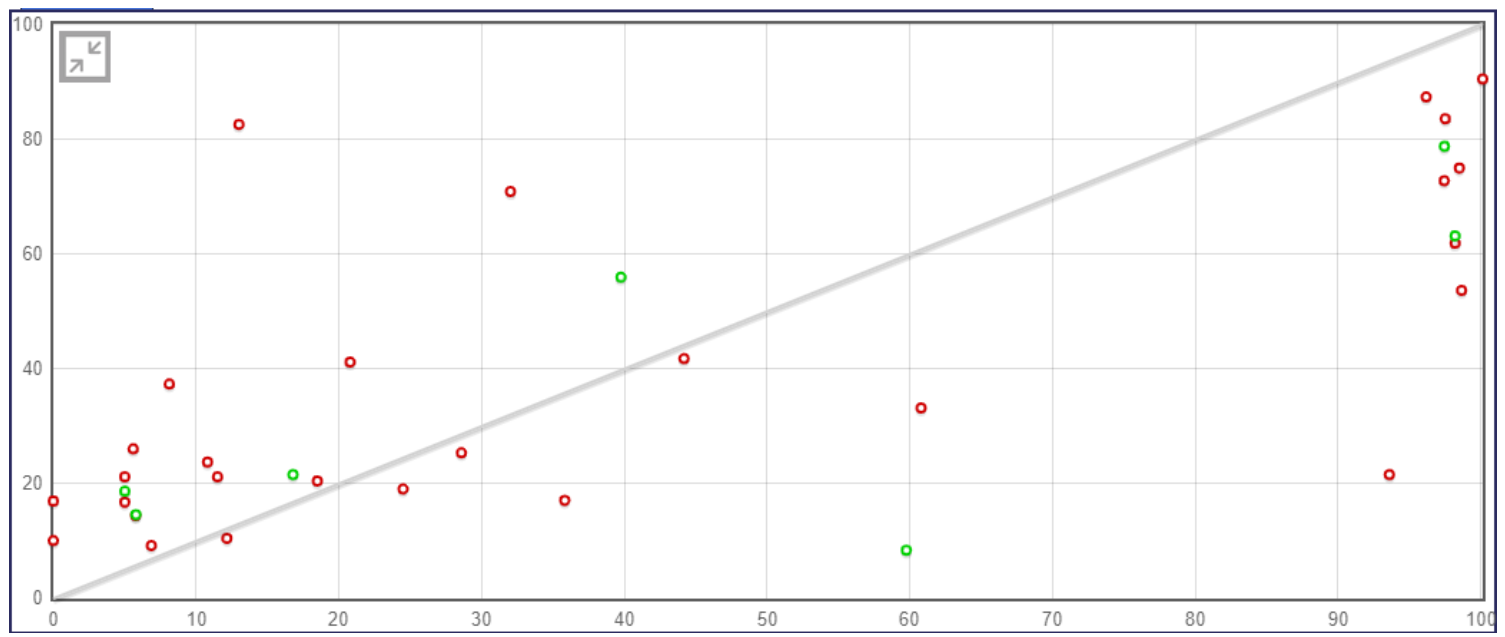

(5)

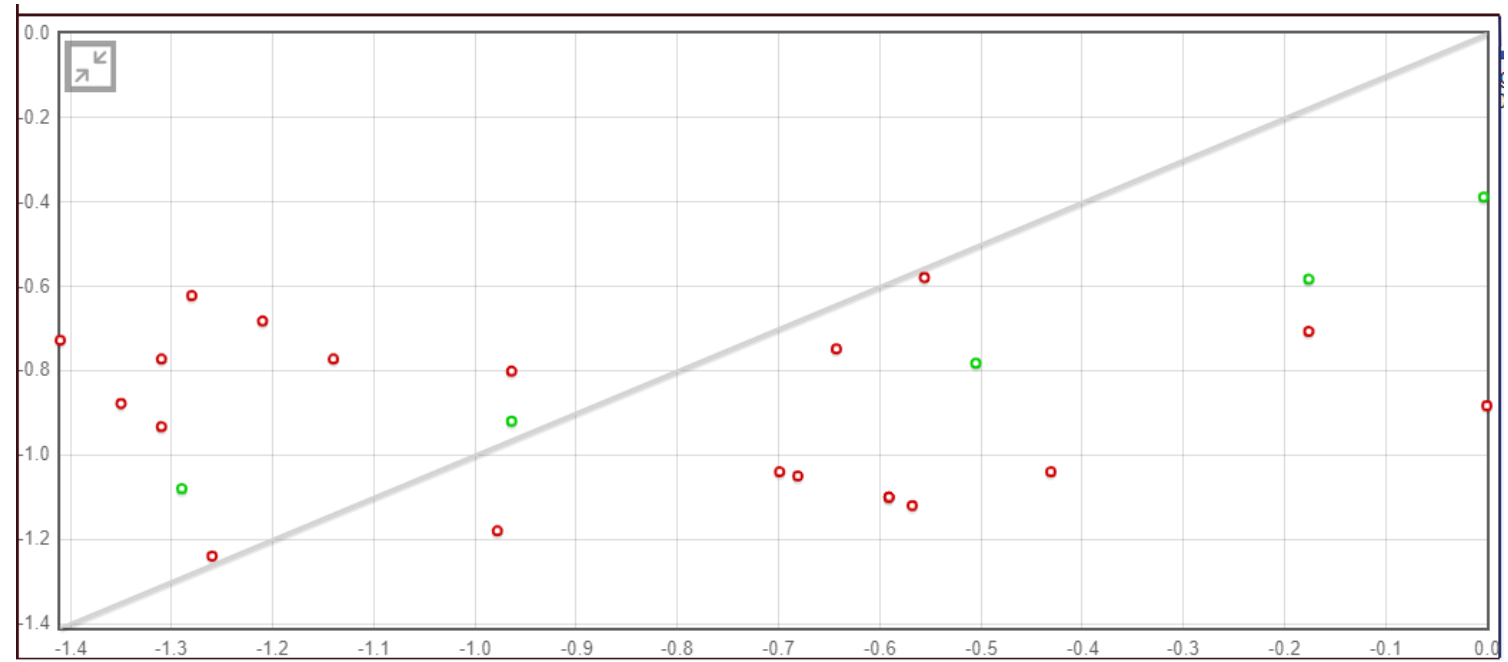

Рис. 3 (продовження). Графіки: (4) - модель на основі методу регресії Random Forest для вибірки № 2; (5) - модель на основі методу регресії Random Forest для вибірки № 3.

ВИСНОВКИ. На основі методів асоціативних нейронних мереж та регресії Random Forest розроблено прогностичні моделі для прогнозування протипаразитарної активності диверсифрікованих похідних 4-тіазолідинонів, для подальшого фрокусування напрямків оптимізації нових біологічно активних молекул із трипаноцидними властивостями.

Роботу виконано за фрінансової підтримки Національного фронду досліджень України (проєкт № 2020.02/0035).

\section{СПИСОК ЛІТЕРАТУРИ}

1. Human African trypanosomiasis / P. Büscher, G. Cecchi, V. Jamonneau, G. Priotto // Lancet. - 2017. 390, Issue 10110. - P. 2397-2409. Access mode : https://doi.org/10.1016/S0140-6736(17)31510-6.

2. Human kinetoplastid protozoan infections: Where are we going next? / A. A. Filardy, K. Guimarães-Pinto, M. P. Nunes [et al.] // Frontiers in Immunology. - 2018. 9. -Art.No. 1493. Accesse mode : https://doi.org/10.3389/ fimmu.2018.01493.

3. Human African trypanosomiasis. [Internet]: https:// www.who.int/data/gho/data/themes/topics/topic-details/ $\mathrm{GHO}$ /ntd-human-african-trypanosomiasis (last access 4.11.2020).
4. Trends in research of antitrypanosomal agents among synthetic heterocycles / A. Kryshchyshyn, D. Kaminskyy, P. Grellier, R. Lesyk // Trends in research of antitrypanosomal agents among synthetic heterocycles. European Journal of Medicinal Chemistry. - 2014. 85. - P. 51-64. Access mode : https://doi.org/10.1016/j. ejmech.2014.07.092.

5. Kryshchyshyn A. Thiazolidinone-related heterocyclic compounds as potential antitrypanosomal agents / A. Kryshchyshyn, D. Kaminskyy, P. Grellier, R. Lesyk // Azoles-Synthesis, Properties, Applications and Perspectives. - IntechOpen. - 2020. Access mode : https://doi. org/10.5772/intechopen.91861. 
6. A review of QSAR studies to discover new druglike compounds actives against leishmaniasis and trypanosomiasis / J. Alberto Castillo-Garit, C. Abad, J. Enrique Rodriguez-Borges [et al.] // Current Topics in Medicinsl Chemistry. - 2012. - 12, Isuue 8. - P. 852-865. Access mode : https://doi.org/10.2174/ 156802612800166756.

7. Activity of Bisphosphonates against Trypanosoma brucei rhodesiense / M. B. Martin, J. M. Sanders, H. Kendrick [et al.] // Journal of Medicinal Chemistry. - 2002. 45, Isuue 14. P. 2904-2914. Access mode : https://doi. org/10.1021/jm0102809.

8. Ferreira L. G. Inhibitors of Trypanosoma brucei trypanothione reductase: comparative molecular field analysis modeling and structural basis for selective inhibition / L. G. Ferreira, A. D. Andricopulo // Future Medicinal Chemistry. - 2013. - 5, Isuue 15. - P. 1753-1762. Access mode : https://doi.org/10.4155/fmc.13.140.

9. Prado-Prado F. J. Multi-target spectral moment QSAR versus ANN for antiparasitic drugs against different parasite species / F. J. Prado-Prado, X. García-Mera, H. González-Díaz // Bioorganic \& Medicinal Chemistry. 2010. - 18, Issue 6. - P. 2225-2231. Access mode : https://doi.org/10.1016/j.bmc.2010.01.068.

10. Unified QSAR \&amp; network-based computational chemistry approach to antimicrobials. II. Multiple distance and triadic census analysis of antiparasitic drugs complex networks / F. J. Prado-Prado, F. M. Ubeira, F. Borges, H. Gonzalez-Diaz // Journal of Computational

\section{REFERENCES}

1. Büscher, P., Cecchi, G., Jamonneau, V., \& Priotto, G. (2017). Human african trypanosomiasis. The Lancet, 390 (10110), 2397-2409. Retrieved from: https:// doi.org/10.1016/S0140-6736(17)31510-6

2. Filardy, A.A., Guimarães-Pinto, K., Nunes, M.P., Zukeram, K., Fliess, L., Pereira, L., Nascimento D.O., Conde L., \& Morrot, A. (2018). Human kinetoplastid protozoan infections: here are we going next? Frontiers in Immunology, 9, 1493. Retrieved from: https://doi. org/10.3389/fimmu.2018.01493.

3. Human African trypanosomiasis. [Internet]: https:// www.who.int/data/gho/data/themes/topics/topic-details/ $\mathrm{GHO} /$ ntd-human-african-trypanosomiasis (last access 4.11.2020)

4. Kryshchyshyn, A., Kaminskyy, D., Grellier, P., \& Lesyk, R. (2014). Trends in research of antitrypanosomal agents among synthetic heterocycles. European Journal of Medicinal Chemistry, 85, 51-64. Retrieved from: https:// doi.org/10.1016/j.ejmech.2014.07.092.

5. Kryshchyshyn, A., Kaminskyy, D., Grellier, P., \& Lesyk, R. (2020). Thiazolidinone-related heterocyclic compounds as potential antitrypanosomal agents. In Azoles-Synthesis, Properties, Applications and Perspectives. IntechOpen. Retrieved from: https://doi. org/10.5772/intechopen.91861.

6. Alberto Castillo-Garit, J., Abad, C., Enrique Rodriguez-Borges, J., Marrero-Ponce, Y., \& Torrens, F. (2012). A review of QSAR studies to discover new druglike compounds actives against leishmaniasis and
Chemistry. - 2010. - 31, Issue 1. - P. 164-173. Access mode : https://doi.org/10.1002/jcc.21292.

11. Online chemical modeling environment (OCHEM): web platform for data storage, model development and publishing of chemical information / I. Sushko, S. Novotarskyi, R. Körner [et al.] // Journal of Computer-aided Molecular Design. - 2011. - 25, Issue 6. - P. 533-554. Access mode : https://doi.org/10.1007/s10822-011-9440-2.

12. Isothiocoumarin-3-carboxylic acid derivatives: Synthesis, anticancer and antitrypanosomal activity evaluation / D. Kaminskyy, A. Kryshchyshyn, I. Nektegayev [et al.] // European Journal of Medicinal Chemistry. - 2014. - 75. - P. 57-66. Access mode : https:// doi.org/10.1016/j.ejmech.2014.01.028.

13. Вивчення протитрипаносомної активності тіазолідинонів та споріднених гетероциклічних систем / А. П. Крищишин, Д. В. Камінський, Н. І. Зеліско [та ін.] // Журн. органічної і фрармацевтичної хімії. - 2013. - 11, № 2. - C. 57-62.

14. Synthesis and antitrypanosomal activity of new 6,6,7-trisubstituted thiopyrano[2,3-d][1,3]thiazoles / N. Zelisko, D. Atamanyuk, O. Vasylenko [et al.] // Bioorganic \& Medicinal Chemistry Letters. - 2012. - 22, Isuue 23. P. 7071-7074. Access mode : https://doi.org/10.1016/j. bmcl.2012.09.091.

15. Thiazolidinone/thiazole based hybrids-New class of antitrypanosomal agents / A. Kryshchyshyn, D. Kaminskyy, O. Karpenko [et al.] // European Journal of Medicinal Chemistry. - 2019. - 174. - P. 292-308. Access mode : https://doi.org/10.1016/j.ejmech.2019.04.052.

trypanosomiasis. Current Topics in Medicinal Chemistry, 12 (8), 852-865. Retrieved from: https://doi. org/10.2174/156802612800166756.

7. Martin, M.B., Sanders, J.M., Kendrick, H., de Luca-Fradley, K., Lewis, J.C., Grimley, J.S., Van Brussel, E.M., Olsen, J.R., Meints, J.A., Burzynska, A., Kafarski, P., Croft, S.L., \& Oldfield, E. (2002). Activity of bisphosphonates against Trypanosoma brucei rhodesiense. Journal of Medicinal Chemistry, 45 (14), 29042914. Retrieved from: https://doi.org/10.1021/jm0102809.

8. Ferreira, L.G., \& Andricopulo, A.D. (2013). Inhibitors of Trypanosoma brucei trypanothione reductase: comparative molecular field analysis modeling and structural basis for selective inhibition. Future Medicinal Chemistry, 5 (15), 1753-1762. Retrieved from: https://doi. org/10.4155/fmc.13.140.

9. Prado-Prado, F.J., García-Mera, X., \& GonzálezDíaz, H. (2010). Multi-target spectral moment QSAR versus ANN for antiparasitic drugs against different parasite species. Bioorganic \& Medicinal Chemistry, 18 (6), 2225-2231. Retrieved from: https://doi.org/10.1016/j. bmc.2010.01.068.

10. Prado-Prado, F.J., Ubeira, F.M., Borges, F., \& González-Díaz, H. (2010). Unified QSAR \& networkbased computational chemistry approach to antimicrobials. II. Multiple distance and triadic census analysis of antiparasitic drugs complex networks. Journal of Computational Chemistry, 31 (1), 164-173. Retrieved from: https://doi.org/10.1002/jcc.21292. 
11. Sushko, I., Novotarskyi, S., Körner, R., Pandey, A.K., Rupp, M., Teetz, W., Brandmaier, S., et al. (2011). Online chemical modeling environment (OCHEM): web platform for data storage, model development and publishing of chemical information. Journal of Computeraided Molecular Design, 25 (6), 533-554. Retrieved from: https://doi.org/10.1007/s10822-011-9440-2.

12. Kaminskyy, D., Kryshchyshyn, A., Nektegayev, I., Vasylenko, O., Grellier, P., \& Lesyk, R. (2014). Isothiocoumarin-3-carboxylic acid derivatives: synthesis, anticancer and antitrypanosomal activity evaluation. European Journal of Medicinal Chemistry, 75, 57-66. Retrieved from: https://doi.org/10.1016/j.ejmech. 2014.01.028.

13. Kryshchyshyn, A.P., Kaminskyy, D.V., Zelisko, N.I., Khyluk, D.V., Grellier, F., \& Lesyk, R.B. (2013). Vyvchennia protytrypanosomnoi aktyvnosti tiazolidynoniv ta spo- ridnenykh heterotsyklichnykh system [The study of the antityrpanosomal activity of thiazolidinones and related heterocyclic systems]. Zhurnal orhanichnoi i farmatsevtychnoi khimii - Journal of Organic and Pharmaceutical Chemistry, 11 (2), 57-62 [in Ukrainian].

14. Zelisko, N., Atamanyuk, D., Vasylenko, O., Grellier, P., \& Lesyk, R. (2012). Synthesis and antitrypanosomal activity of new 6, 6, 7-trisubstituted thiopyrano [2, 3-d][1, 3] thiazoles. Bioorganic \& Medicinal Chemistry Letters, 22 (23), 7071-7074. Retrieved from: https://doi. org/10.1016/j.bmcl.2012.09.091.

15. Kryshchyshyn, A., Kaminskyy, D., Karpenko, O., Gzella, A., Grellier, P., \& Lesyk, R. (2019). Thiazolidinone/ thiazole based hybrids-New class of antitrypanosomal agents. European Journal of Medicinal Chemistry, 174, 292-308. Retrieved from: https://doi.org/10.1016/j.ejmech.2019.04.052.

\title{
ЛЬВОВСКИЙ НАЦИОНАЛЬНЫЙ МЕДИЧИНСКИЙ УНИВЕРСИТЕТ А.П. Крищишин-Дилевич
}

\section{QSAR-АНАЛИЗ БИБЛИОТЕК 4-ТИАЗОЛИДИНОН-РОДСТВЕННЫХ ГЕТЕРОЦИКЛОВ ДЛЯ ПРОГНОЗИРОВАНИЯ ПРОТИВОТРИПАНОСОМНЫХ СВОЙСТВ НОВЫХ ПРОИЗВОДНЫХ}

\begin{abstract}
Резюме
Вступление. Производные тиазолидинона и родственных гетероциклов являются источником новых противопаразитарных агентов, в том числе молекул с противотрипаносомными свойствами. В актуальных научных источниках найден ряд исследований о количественной взаимосвязи структура - антитрипаносомная активность, что включают различные подходы компьютерной химии. Большинство исследований относится к так называемым мультитаргетным, когда в выборку включают результаты других видов противопаразитарных активностей. Разработка новых QSAR-моделей производных тиазолидинона с противотрипаносомными свойствами позволит определить направления направленного дизайна новых противопаразитарных агентов на основе циклов тиазола и тиазолидинона.

Цель исследования - установить количественную взаимосвязь структура - противотрипаносомная активность в пределах библиотек тиазолидинонов и родственных гетероциклов.

Методы исследования. Построение математических моделей на основе QSAR-анализа осуществляли с помощью онлайн-платформы Online Chemical Database.

Результаты и обсуждение. Анализ количественной взаимосвязи структура -противотрипаносомная активность проводили с применением математической модели ассоциативных нейронных сетей (ASNN: Associative Neural Networks) и метода регрессии Random Forest (RFR: Random Forest regression) на основе выборок, включавших производные изотиокумарин-3-карбоновых кислот, тиопиранотиазолов и 4-тиазолидинон-имидазотиадиазолов с установленной трипаноцидной активностью в отношении Trypanosoma brucei brucei и Trypanosoma brucei gambiense. Лучшую прогнозирующую способность для группы изотиокумарин-3-карбоновых кислот и тиопирано[2,3-d][1,3]тиазол-2-онов вычислено с помощью алгоритма Random Forest. Модель, вычисленная на основе алгоритма Random Forest для группы имидазотиадиазолов, обладает наиболее высокой прогнозирующей способностью со значением $R^{2}=0,96$.

Вывод. На основе методов ассоциативных нейронных сетей и регрессии Random Forest разработаны прогностические модели для прогнозирования противопаразитарной активности диверсифицированных производных 4-тиазолидинонов и последующей фрокусировки направлений оптимизации новых биологически активных молекул с трипаноцидными свойствами.
\end{abstract}

КЛЮЧЕВЫЕ СЛОВА: QSAR-анализ; метод ассоциативных нейронных сетей; метод регрессии Random Forest; тиазолидоны; противотрипаносомная активность. 


\section{QSAR-ANALYSIS OF THE 4-THIAZOLIDINONE-RELATED HETEROCYCLES FOR THE PREDICITING OF ANTITRIPANOSOMAL PROPERTIES OF NOVEL DERIVATIVES}

\section{Summary}

Introduction. Derivatives of thiazolidinone and related heterocycles are a source of new antiparasitic agents, including molecules with antitrypanosomal properties. A number of studies of the quantitative structure antitrypanosomal activity relationship based on different approaches of computer chemistry have been found in the relevant scientific sources. Although most studies belong to the so-called-multitarget, when the studied set include the results of other types of antiparasitic activities. Development of new QSAR-models of thiazolidinone derivatives with antitrypanosomal properties will allow to outline the directions of directed design of new antiparasitic agents based on thiazole and thiazolidinone cycles.

The aim of the study - to establish quantitative relationships between structure-antitrypanosomal activity within libraries of thizolidinones and related heterocycles.

Research Methods. The development of mathematical models based on QSAR-analysis was performed using the online platform Online Chemical Database.

Results and Discussion. Analysis of the quantitative structure-activity relationship was performed using a mathematical model of associative neural networks (ASNN: Associative Neural Networks) and the Random Forest regression method (RFR: Random Forest regression) based on set of compounds including isothiocoumarin3-carboxylic acid derivatives, thiopyranothiazoles and 4-thiazolidinone-imidazothiadiazoles with the established trypanocidal activity against Trypanosoma brucei brucei and Trypanosoma brucei gambiense. The best predictive capacity for the group of isothiocoumarin-3-carboxylic acids and thiopyrano[2,3-d][1,3]thiazol-2-ones was calculated using the Random Forest algorithm. The model calculated on the basis of the Random Forest algorithm for the group of imidazothiadiazoles has the highest predictive power with a value of $R^{2}=0.96$.

Conclusions. Based on the methods of associative neural networks and Random Forest regression, a series of prognostic models have been developed for the predicting of antiparasitic activity of different 4-thiazolidinone derivatives and further development of the optimization directions for novel biologically active molecules with trypanocidal properties.

KEY WORDS: QSAR analysis; associative neural network method; Random Forest regression method; thiazolidones; antitrypanosomal activity.

Адреса для листування: А. П. Крищишин-Дилевич, Львівський національний медичний університет імені Данила Галицького, вул. Пекарська, 69, Львів, 79010, Україна, e-mail: kryshchyshyn.a@gmail.com. 